\title{
Application of QuEChERS Pesticide Multiresidue Method in Traditional Saudi Medicine and Analysis by Gas Chromatography Mass Spectrometry
}

\author{
A. Al-Othman, Sherif H. Abd-Alrahman, and Nasser Al-Daghri
}

\begin{abstract}
The Quick Easy Cheap Effective Rugged and Safe multiresidue method (QuEChERS) has been validated for the extraction of 9 organochlorine pesticides (OCPs) in different matrices of traditional Saudi medicine plants (TSMP). The nine OCPs were hexachlorohexane isomers $(\mathrm{HCH}$, including $\alpha$-BHC, $\beta$-BHC, $\gamma$-BHC,), heptachlor, heptachlor-epoxide, and DDT derivatives (o,p-DDE, p,p-DDE, o,p-DDT, p,p-DDT). The method employed a rapid, simple and cost effective procedure. The spiking levels for the recovery experiments were $0.1,0.5$ and $2.0 \mathrm{mg} \mathrm{kg}-1$. Mean recoveries mostly ranged from $82.0 \%$ to $104.0 \%(93.0 \%$ on average), while the linearity for 9 OCPs, in the working standard solutions of six concentration levels between 1 and $100 \mathrm{ng} / \mathrm{ml}$, varied from 0.989 to 0.999 . Precision, expressed as relative standard deviation (RSD) were generally below $10 \%(4.72 \%$ on average). Based on these results, the methodology was shown to be robust and highly efficient and thus, suitable for monitoring MRL compliance in a wide range of commodity. The contamination status of 9 OCPs on different TSMPs fenugreek, ginger cloves and cinnamon marketed in Riyadh, Saudi Arabia. Among a total of 48 samples which were also tested using a previously validated method, $31.0 \%$ (15 samples) contained at least one of the 9 pesticides. We conclude that QuEChERS is a valid method suitable for investigate of OCPs residues in TSMPs.
\end{abstract}

Index Terms-Organochlorine pesticides, QuEChERS, medicinal plant, Saudi Arabia.

\section{INTRODUCTION}

Saudi Arabia is one of the richest biodiversity areas in the Arabian Peninsula and comprises very important genetic resources of crop and medicinal plants. In addition to its large number of endemic species, the components of the flora are the admixture of the elements of Asia, Africa and the Mediterranean region [1]. According to Collenette [2], the greatest species diversity has been observed in Asir and Hijaz, the western mountainous area of the Kingdom, which borders the Red Sea. And it is due to a greater rainfall and range of altitude from sea level to $9300 \mathrm{ft}$ at Jabal Sawdah, near Abha. A total of 2250 species in 142 families are represented in the flora of the Kingdom of Saudi Arabia [2]. Of these, there are

Manuscript received October 28, 2014; revised January 15, 2015.

A. Al-Othman and Nasser Al-Daghri are with the Prince Mutaib Chair for Biomarkers of Osteoporosis, King Saud University PO Box 2455, Riyadh, 11451, Saudi Arabia; College of Applied Medical Sciences, King Saud University; King Saud University, Riyadh 11451, Saudi Arabia (e-mail: aalothman @ksu.edu.sa,ndaghri@ksu.edu.sa).

Sherif H. Abd-Alrahman is with the Biomarkers Research Program, King Saud University, PO Box 2455, Riyadh, 11451, Saudi Arabia.;Pesticides Residues and Environmental Pollution Dept., Central Agricultural Pesticide Laboratory, Agricultural Research Center, Giza 12618, Egypt (e-mail: drsherif_hussein@yahoo.com).
242 endemic and 600 rare and endangered species in the wild; thus an action plan should be taken for their conservation and sustainable development. According to Al-Yahya [3], the Arabian peninsula is the birth place of herbal drugs, and the use of folk medicine has existed there since time immemorial. According to Mossa [4], the Kingdom of Saudi Arabia is gifted with a wide range of flora, consisting of a large number of medicinal herbs, shrubs and trees. It has been estimated that the flora of Saudi Arabia have a great medicinal species diversity expected to be more than 1200 (over 50\%) out of its 2250 species. Some sporadic publications on the folk medicines of Saudi Arabia [3]-[5] are available.

Indigenous knowledge (IK) of uses of plants of Saudi Arabia for the cure of many ailments is ancient and still available among the tribal and local people and medicinal healers (Hakim). These IK and traditional experiences are disappearing day by day with development and modernization. There is, therefore, an urgent need to document these vast stores of knowledge through ethnobotanical surveys throughout the Kingdom before their disappearance from the community.

Organochlorine pesticides (OCPs) were widely used in agriculture starting in the early 1950s, and most OCPs are resistant to photochemical, biological and chemical degradation for a long period of time [6]. They persist in various media and some can be transported over long distances to regions where they have never been used. The use of most OCPs is now prohibited in China, but their low biodegradability means that they can still be detected in the environment [7]. Because many herbs such as American ginseng are plant materials, they carry a risk of contamination from agricultural chemicals [8]. Therefore, residuals of environmentally persistent pesticides may be carried by the plants and soil to varying degrees. To date, a maximum residue level has not been set for American ginseng [9], and only a few analytical methods for determining pesticide residues in herbs have been reported [10], [11]. In addition, the method of preparing sample solutions is troublesome because of the complex chemical composition and certain sample matrices. As a result, techniques that combine a short analysis time, sufficient selectivity and adequate sensitivity have become necessary.

The Quick Easy Cheap Effective Rugged and Safe multiresidue method (QuEChERS) is a novel sample preparation methodology for pesticide multiresidue analysis that was developed between 2000 and 2002 and first reported in 2003 [12]. Although a very new method, it has already been widely accepted by the international community of pesticide residue analysis, and many publications already 
deal with this method in its original form or variations [10], [13]-[15]. Additional advantages of the method include the high sample throughput and the low amounts of solvent, glassware, and bench space required [16].

In this study, we employed a modified QuEChERS method, in combination with gas chromatography (GC), for the analysis of the contamination status of 14 OCPs in 60 samples, taken from six different areas (including Canada, America, Hebei Province, Shangdong Province, Liaoning Province and Beijing City in China).

\section{EXPERIMENTAL}

\section{A. Reagents and Standards}

All OCP standards $\alpha$-HHC, $\beta$-HHC, $\gamma$-HHC, heptachlor, heptachlor-epoxide, o,p-DDE, p,p-DDE, o,p-DDT and p,p-DDT, (purity $\square$ 98\%) were obtained from Sigma Germany. A stock solution of each pesticide was prepared by dissolving $10 \mathrm{mg}$ with $50 \mathrm{ml}$ of $\mathrm{n}$-hexane in volumetric flask. The concentration of the stock solution was $1000 \mathrm{ng} / \mathrm{ml}$ for all pesticides. All the solvents used, including acetonitrile, petroleum ether $\left(60-90^{\circ} \mathrm{C}\right)$ and methanol, were analytical grade. Graphitized carbon black (GCB), primary secondary amine (PSA), sodium acetate and anhydrous $\mathrm{MgSO} 4$ were also manufactured by Supelco Co.

\section{B. Sampling}

A total of 48 samples of four different medicinal plants (fenugreek, ginger, cloves and cinnamon) were collected from markets Riyadh, Saudi Arabia. All samples were milled (particle size about $2 \mathrm{~mm}$ ) and stored at $-18^{\circ} \mathrm{C}$ prior to analyses for OCPs.

\section{Extraction and Clean-up}

Extraction and clean-up were carried out according to a modified version of the QuEChERS method. Two grams of sample flour were weighed into the 50-ml centrifuge tubes. The main extraction involved the addition of $20 \mathrm{ml}$ of acetic acid-water-acetonitrile (1:5:94, v/v). The tube was closed and shaken vigorously by hand for $1 \mathrm{~min}$. To induce phase separation and pesticide partitioning, a buffer-salt mixture (consisting of $0.5 \mathrm{~g}$ sodium acetate and $3 \mathrm{~g}$ anhydrous $\mathrm{MgSO} 4)$ was added to the suspension. The tube was closed, shaken vigorously by hand for $1 \mathrm{~min}$, and centrifuged for 5 $\min$ at $650 \mathrm{~g}$. For clean-up, $1.5 \mathrm{ml}$ of the upper organic phase was transferred into a 2-ml centrifugation tube already containing $25 \mathrm{mg}$ PSA, $50 \mathrm{mg} \mathrm{GCB}$ and $150 \mathrm{mg}$ anhydrous $\mathrm{MgSO} 4$. The tube was closed, shaken vigorously by hand for $1 \mathrm{~min}$, and centrifuged at $5000 \mathrm{rpm}$ for $5 \mathrm{~min}$. An aliquot of the upper organic phase (about $1 \mathrm{ml}$ ) was transferred into a vial for GC/MS analyses.

\section{GC Analyses}

An Agilent 7890N gas chromatograph (Agilent, Ltd, USA) equipped with $63 \mathrm{Ni}$ electron capture detection (ECD) system and 7683B Series injector was used. Nitro-gen of purity greater than $99.99 \%$ was used as carrier gas. For separation, a fused-silica capillary column DB-5 $(30 \mathrm{~m} \times 0.25 \mathrm{~mm}$ i.d., film thickness $0.25 \mu \mathrm{m}$ ), Agilent) was employed. The column temperature was maintained at $80{ }^{\circ} \mathrm{C}$ for $1 \mathrm{~min}$, and then ramped at $10{ }^{\circ} \mathrm{C} / \mathrm{min}$ up to $250{ }^{\circ} \mathrm{C}$ and kept for $20 \mathrm{~min}$. The total run time was $20 \mathrm{~min}$ at a constant flow rate of 1.5 $\mathrm{ml} / \mathrm{min}$. The injector temperature was $250{ }^{\circ} \mathrm{C}$ and the detector temperature was $260{ }^{\circ} \mathrm{C}$. The sample injection volume was $1 \mu 1$.

\section{RESUlTS AND DISCUSSION}

Standard calibration curves were obtained by plotting analyte concentrations against the peak area. The linearity for 9 OCPs, in the working standard solutions of seven concentration levels between 1 and $100 \mathrm{ng} / \mathrm{ml}$, varied from 0.989 to 0.999 . The calibration curves were sufficient for the detection of 9 OCPs in American ginseng samples. Precision and limit of detection (LOD) are shown in Table I. The accuracy and precision of the method were sufficiently high, spiked within the range of $0.1-1 \mathrm{ng} / \mathrm{g}$. The recovery values oscillated between 86\% ( $\alpha$-BHC), 82\% ( $\beta$-BHC), 87.3\% $(\gamma$-BHC), 96.1\% (heptachlor), 102\% (heptachlor-epoxide), $97.8 \%(o, p$-DDE) and 104\% ( $p, p$-DDE), 95.5\% ( $o, p$-DDT $)$ and $97.2 \%(p, p$-DDT) at three levels added (0.1, 0.5 and 2 $\mathrm{ng} / \mathrm{g}$, respectively), and relative standard deviations (RSD) were generally below $8.0 \%$. The LODs were between 0.15 and $0.35 \mathrm{ng} / \mathrm{g}$, based on a signal-to-noise ratio of $3: 1$.

TABLE I: PRECISION, LOD, LINEARITY RANGES AND RECOVERY \% OF VARIOUS TESTED PESTICIDES.

\begin{tabular}{lcccc}
\hline \multicolumn{1}{c}{ Pesticide } & $\begin{array}{c}\text { Precision } \\
(\mathrm{RSD} \%)\end{array}$ & $\begin{array}{c}\text { LOD } \\
(\mathrm{ng} / \mathrm{ml})\end{array}$ & $\begin{array}{c}\text { Linear range } \\
(\mathrm{ng} / \mathrm{ml})\end{array}$ & Rec. \% \\
\hline$\alpha$-HCH & 4.83 & 0.05 & $1-100$ & 86 \\
$\beta$-HCH & 6.52 & 0.05 & $1-100$ & 82 \\
$\gamma$-HCH & 4.55 & 0.05 & $1-500$ & 87.1 \\
Heptachlor & 3.26 & 0.02 & $1-100$ & 96.1 \\
Heptachlor-ep & 3.56 & 0.02 & $1-100$ & 102 \\
oxide & 5.63 & 0.01 & $1-100$ & 97.8 \\
$O, P$-DDE & 5.48 & 0.01 & $1-100$ & 104 \\
$P, P$-DDE & 4.52 & 0.01 & $1-100$ & 95.5 \\
$O, P$-DDT & 5.12 & 0.01 & $1-100$ & 97.2 \\
$P, P$-DDT & & & & \\
\hline
\end{tabular}

The methodology was applied to the analysis of medicinal plant samples collected from different markets in Riyadh, Saudi Arabia during 2012. In the present study, nine out of 48 samples contained at least one of the 9 pesticides, as shown in Table II. None of the 48 samples contained all 9 tested pesticides. None of the hexachlorohexane isomers $(\alpha-\mathrm{BHC}$, $\beta$-BHC, $\gamma$-BHC), heptachlor, heptachlor-epoxide, and DDT derivatives ( $o, p$-DDE, $p, p$-DDE, $o, p$-DDT, $p, p$-DDT) were detected at over $26 \mathrm{ng} / \mathrm{g}$ in one sample. Results indicated that ginger showed that the highest mean concentration of the 9 tested OCPs were $13.60(0-22.6) \mathrm{ng} / \mathrm{g}$ and $30.21(0-25.75)$ $\mathrm{ng} / \mathrm{g}$ for $\Sigma \mathrm{HCHs}$ and $\Sigma \mathrm{DDT}$, respectively. The $\Sigma \mathrm{HCH}$ are $6.64(0-9.62) \mathrm{ng} / \mathrm{g}, 4.41(0-4.42) \mathrm{ng} / \mathrm{g}$ and $3.17(0-3.45) \mathrm{ng} / \mathrm{g}$, in cinnamon, fenugreek and cloves, respectively, while EDDTs are $17.35(0-13.68) \mathrm{ng} / \mathrm{g}, 15.5(0-10.42) \mathrm{ng} / \mathrm{g}$ and 14.89 (0-18.47) ng/g, in cloves, cinnamon and fenugreek, respectively. Frequency (positive samples \%) of 9 tested OCPs were $17 \%$ (8 samples), $25 \%$ (12 samples), $6 \%$ (3 samples), $7 \%$ (3 samples), $9 \%$ (4 samples), $27 \%$ (13 
samples), $31 \%$ (15 samples), $7 \%$ (3 samples), and $8 \%$ (4 samples), of analysed samples, for $\alpha$-BHC, $\beta$-BHC, $\gamma$-BHC, heptachlor, heptachlor-epoxide, $o, p$-DDE, $p, p$-DDE, $o$, $p$-DDT and $p, p$-DDT, respectively.

TABLE II: ORgANOCHLORINE PESTICIDES CONTAMINATION OF FENUGREEK, Ginger, Cloves AND CINNAMON COLleCted From SAUDI MARKETS

\begin{tabular}{|c|c|c|c|c|c|}
\hline Pesticide & Fenugreek & Ginger & Cloves & $\begin{array}{c}\text { Cinnam } \\
\text { on }\end{array}$ & $\begin{array}{c}\text { Frequency } \\
\%\end{array}$ \\
\hline$\alpha-\mathrm{HCH}$ & $\begin{array}{c}1.52 \\
(0-2.55)\end{array}$ & $\begin{array}{c}3.56 \\
(0-7.23)\end{array}$ & $\begin{array}{c}0.78 \\
(0-1.64)\end{array}$ & $\begin{array}{c}2.32 \\
(0-5.64)\end{array}$ & 17 \\
\hline$\beta$-HCH & $\begin{array}{c}0.78 \\
(0-1.52)\end{array}$ & $\begin{array}{c}2.15 \\
(0-4.85)\end{array}$ & $\begin{array}{c}1.45 \\
(0-3.45)\end{array}$ & $\begin{array}{c}3.46 \\
(0-9.62)\end{array}$ & 25 \\
\hline$\gamma-\mathrm{HCH}$ & $\begin{array}{c}2.11 \\
(0-4.42)\end{array}$ & $\begin{array}{c}7.89 \\
(0-22.6 \\
0)\end{array}$ & $\begin{array}{c}0.94 \\
(0-2.97)\end{array}$ & $\begin{array}{c}0.85 \\
(0-2.18)\end{array}$ & 6 \\
\hline$\Sigma \mathrm{HCHs}$ & 4.41 & 13.60 & 3.17 & 6.64 & - \\
\hline $\begin{array}{l}\text { Heptachlo } \\
\mathrm{r}\end{array}$ & $\begin{array}{c}1.35 \\
(0-3.23)\end{array}$ & $\begin{array}{c}2.25 \\
(0-6.94)\end{array}$ & $\begin{array}{c}1.59 \\
(0-2.28)\end{array}$ & $\begin{array}{c}2.38 \\
(0-6.42)\end{array}$ & 7 \\
\hline $\begin{array}{l}\text { Heptachlo } \\
\text { r-epoxide }\end{array}$ & $\begin{array}{c}0.52 \\
(0-2.65)\end{array}$ & $\begin{array}{c}1.36 \\
(0-3.84)\end{array}$ & $\begin{array}{c}2.35 \\
(0-4.46)\end{array}$ & $\begin{array}{c}3.66 \\
(0-6.85)\end{array}$ & 9 \\
\hline$O, P$-DDE & $\begin{array}{c}5.12 \\
(0-12.38)\end{array}$ & $\begin{array}{c}14.56 \\
(0-25.7 \\
5)\end{array}$ & $\begin{array}{c}7.26 \\
(0-13.6 \\
8)\end{array}$ & $\begin{array}{c}4.12 \\
(0-10.4 \\
2)\end{array}$ & 27 \\
\hline$P, P$-DDE & $\begin{array}{c}6.45 \\
(0-18.47)\end{array}$ & $\begin{array}{c}8.94 \\
(0-23.2 \\
1)\end{array}$ & $\begin{array}{c}4.35 \\
(0-11.4 \\
4)\end{array}$ & $\begin{array}{c}3.95 \\
(0-7.35)\end{array}$ & 31 \\
\hline$O, P$-DDT & $\begin{array}{c}0.56 \\
(0-1.96)\end{array}$ & $\begin{array}{c}2.15 \\
(0-6.44)\end{array}$ & $\begin{array}{c}1.25 \\
(0-2.75)\end{array}$ & $\begin{array}{c}0.54 \\
(0-1.23)\end{array}$ & 7 \\
\hline$P, P$-DDT & $\begin{array}{c}0.89 \\
(0-2.34)\end{array}$ & $\begin{array}{c}0.95 \\
(0-2.73)\end{array}$ & $\begin{array}{c}0.55 \\
(0-2.25)\end{array}$ & $\begin{array}{c}0.85 \\
(0-1.56)\end{array}$ & 8 \\
\hline$\Sigma$ DDTs & 14.89 & 30.21 & 17.35 & 15.5 & - \\
\hline
\end{tabular}

Although the pesticide was detected, the level was lower than the maximum allowable residual limits (MRLs) established by the China Pharmacopoeia Committee (total BHC $200 \mathrm{ng} / \mathrm{g}$, heptachlor and heptachlor-epoxide $100 \mathrm{ng} / \mathrm{g}$ and total DDT $200 \mathrm{ng} / \mathrm{g}$, for different medicinal herbs, 2010).

We expect that more attention will be paid to monitoring the presence of pesticide residues to guarantee high quality of medicinal herbs in Saudi Arabia. Our results suggest that contamination of medicinal herbs with OCPs is widespread. The MRLs for OCPs commonly found in tested Saudi old medicinal herbs and other herbs should be established as quickly as possible. The apparent current explosion of interest in commercial utilization of Saudi medicinal herbs should be accompanied by accurate quality control. Prompt analytical methods would be very useful for setting up realistic MRLs and other regulatory guidelines in the management of pesticide residues in herb products.

\section{CONCLUSION}

The proposed QuEChERS procedure was successfully applied to the sample preparation of 9 OCPs from medicinal herbs. This method showed satisfactory validation parameters, such as accuracy, precision and lower limits of detection. For all of pesticides studied, the sensitivity of the method was good enough to ensure reliable determination at levels lower than the respective MRLs. The proposed method was applied for the determination of pesticide levels in 48 samples collected from different markets. OCPs were found at different levels in the samples investigated. The present study provides significant data on OCP contamination in Saudi herbs and helps in risk assessment of consumer exposure to the expected OCP levels.

\section{ACKNOWLEDGMENT}

The authors gratefully acknowledge the National Plan for Sciences and Technology (NPST) for the financial support (10-ENE995-02).

\section{REFERENCES}

[1] M. A. Rahman, J. S. Mossa, M. S. A. Said, and M. A. A. Yahya, "Medicinal plant diversity in the flora of Saudi Arabia, a report on seven plant families," Fitoterapia, vol. 75, no. 2, pp. 149-61, 2004.

[2] S. Collenette, "Checklist of botanical species in Saudi Arabia," International Asclepiad Society, UK, pp. 78, 1998.

[3] M. A. A. Yahya, Proc. III, Int. Conf. Islamic Medicine, Kuwait, 1984.

[4] J. Mossa, M. A. Yahya, and I. A. Meshal, "Medicinal plants of Saudi Arabia,” Riyadh, King Saud University, 1987.

[5] Saudi Plants Used in Traditional Medicine, 1987.

[6] P. A. Vagi-MC, M. N. Kostopoulou, M. K. Karamanoli, and T. D. Lekkas, "Determination of organochlorine pesticides in marine sediments samples using ultrasonic solvent extraction followed by GC/ECD," Desalination, vol. 210, pp. 146-56, 2007.

[7] M. B. Pereira, E. C. Grana, M. J. G. Castro, S. M. Lorenzo, P. L. Mahia, D. P. Rodriguez et al., "Microwave-assisted extraction versus Soxhlet extraction in the analysis of 21 organochlorine pesticides in plants," Journal of Chromatography, vol. 1008, pp. 115-122, 2003.

[8] Y. C. Ling, H. C. Teng, and C. Cartwright, "Supercritical fluid extraction and clean-up of organochlorine pesticides in Chinese herbal medicine," Journal of Chromatography A, vol. 835, no. 1-2, pp. 145-157, 1999.

[9] Chinese Pharmacopoeia, 2010.

[10] N. Yoshioka, Y. Akiyama, T. Mitsuhashi, H. Hatanaka, M. Tsuji, and S. Matsushita, "Analysis of pesticide residues in ginseng and senna," Iyakuhin Kenkyu, vol. 31, pp. 225-231, 2000.

[11] S. Shioda, T. Hamano, J. Nakajima, J. Shimomura, D. Suetsugu, and I. Yasuda, "Organophosphorus and pyrethroid pesticide residues in the crude drugs and the decoction," Annu. Rep. Tokyo, Metrop. Inst. Public Health, vol. 55, pp. 43-47, 2004.

[12] M. Anastassiades, S. J. Lehotay, D. Stajnbaher, and F. J. Schenck, "Fast and easy multiresidue method employing acetonitrile extraction/partitioning and 'dispersive solid-phase extraction' for the determination of pesticide residues in produce," Journal of AOAC International, vol. 86, no. 2, pp. 412-31, 2003.

[13] S. J. Lehotay, K. Mastovska, and S. J. Yun, "Evaluation of two fast and easy methods for pesticide residue analysis in fatty food matrixes," Journal of AOAC International, vol. 88, no. 2, pp. 30-38, 2005.

[14] F. J. Schenck and J. E. Hobbs, "Evaluation of the quick, easy, cheap, effective, rugged, and safe (QuEChERS) approach to pesticide residue analysis," Bulletin of Environmental Contamination and Toxicology, vol. 73, no. 1, pp. 24-30, 2004.

[15] A. Hercegova, M. Domotorova, D. Kruzlicova, and E. Matisova, "Comparison of sample preparation methods combined with fast gas chromatography-mass spectrometry for ultra-trace analysis of pesticide residues in baby food," Journal of Separation Science, vol. 29, no. 8, pp. 1102-1109, 2006.

[16] P. Paya, M. Anastassiades, D. Mack, I. Sigalova, B. Tasdelen, J. Oliva et al., "Analysis of pesticide residues using the Quick Easy Cheap Effective Rugged and Safe (QuEChERS) pesticide multiresidue method in combination with gas and liquid chromatography and tandem mass spectrometric detection," Analytical and Bioanalytical Chemistry, vol. 389, no. 6, pp. 1697-714, 2007.

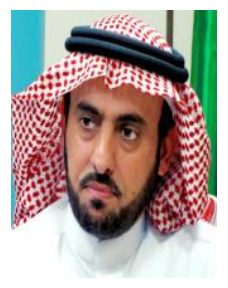

A. Al-Othman is a Ph.D in applied medical sciences. His main research field is medical nutrition. He is a member of "Prince Mutaib Chair for Biomarkers of Osteoporosis research chair", King Saud University PO Box 2455, Riyadh, 11451, Saudi Arabia. Also he is a faculty member of college of Applied Medical Sciences, King Saud University, Riyadh 11451, Saudi Arabia. 


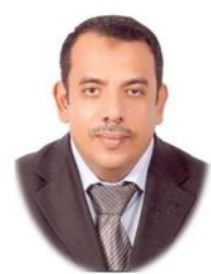

Sherif H. Abd-Alrahman received his Ph.D in analytical chemistry, in 2005. His main research field is pesticides residues and environmental pollution. He is a member of "Biomarkers Research Program", King Saud University, PO Box 2455, Riyadh, 11451, Saudi Arabia Also he is a researcher of Pesticides Residues and Environmental Pollution Dept., Central Agricultural Pesticide Laboratory, Agricultural Research Center, Giza 12618, Egypt. His current research interests is POPs exposure and chronic diseases.

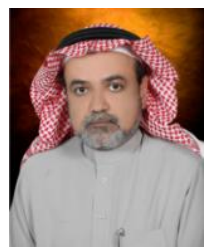

Nasser Al-Daghri is a $\mathrm{PhD}$ in clinical biochemistry. The main research field is pesticides residues and environmental pollution. $\mathrm{He}$ is a member of "Biomarkers Research Program", King Saud University, PO Box 2455, Riyadh, 11451, Saudi Arabia $\mathrm{He}$ is a head manager of "Prince Mutaib Chair for Biomarkers of Osteoporosis research chair", King Saud University PO Box 2455, Riyadh, 11451, Saudi Arabia. Also he is a faculty member of College of Sciences, King Saud University, Riyadh 11451, Saudi Arabia. His current research interests is biomarkers of chronic diseases. 
